\title{
'KORIDOR KARANGWANGI' SEBAGAI STRATEGI PENGEMBANGAN WISATA KEKINIAN YANG BERBASIS BUDAYA KOTA CIREBON
}

\author{
Yoyon Indrayana \\ Program Doktor Administrasi Publik, Fakultas Ilmu Sosial dan Ilmu Politik, \\ Universitas Diponegoro, Semarang, Indonesia. \\ yo.indra@gmail.com
}

\begin{abstract}
The city of Cirebon has a lot of potential for both tangible and intangible historical cultural heritages, so it is only right that the Cirebon city government makes all the riches of historical cultural heritage as a potential for future tourism. A comprehensive and integrated effort is needed in developing the city of Cirebon as a city for cultural tourism by involving many stakeholders, both from the government, DPRD, private sector, community and also actors of art and culture, so that Cirebon City can become a leading cultural tourism city. The large number of cultural potentials it has compared to other areas in West Java Province, makes Cirebon City has a very big opportunity to become a city for cultural tourism that is superior to others. With so many cultural heritages from various historical periods that are owned, there is no doubt that the superiority of cultural heritage values in the city of Cirebon has a very high value and must be preserved and maintained as part of the effort to preserve the nation's culture. In order to further increase tourism in the city of Cirebon, contemporary tourist destinations need to be developed to serve the desires and tastes of tourists. The Karangwangi Corridor can be a strategy for developing cultural tourism that can be done. Several attempts to make it happen, such as; physical arrangement of roads that are good and beautiful, engineering traffic so they don't get jammed, arrangement of pedestrians so that pedestrians feel comfortable, arrangement of green open spaces so that the area becomes shady, arrangement of street furniture that adds to the aesthetics of the road, arrangement of city lights as lighting, arrangement billboards to be orderly and beautiful, and so on.
\end{abstract}

Keywords: cultural potential, cultural tourism, contemporary tourism, Karangwangi corridor.

\begin{abstract}
Abstrak
Kota Cirebon memiliki banyak potensi peninggalan budaya sejarah baik yang bersifat tangible maupun intangible, sehingga sudah sepantasnyalah kalau pemerintah daerah kota Cirebon menjadikan semua kekayaan peninggalan budaya sejarah tersebut sebagai potensi wisata unggulan pada masa yang akan datang. Perlu upaya yang komprehensif dan terpadu dalam mengembangkan kota Cirebon sebagai kota wisata budaya dengan melibatkan banyak stakeholders, baik dari unsur pemerintah, DPRD, swasta, masyarakat dan juga para pelaku seni dan budaya, agar Kota Cirebon dapat menjadi kota wisata budaya unggulan. Banyaknya potensi budaya yang dimiliki dibanding dengan wilayah-wilayah lain di Provinsi Jawa Barat, menjadikan Kota Cirebon memiliki peluang yang sangat besar untuk menjadi kota wisata budaya yang unggul dibanding yang lain. Dengan banyaknya warisan budaya dari berbagai periode sejarah yang dimiliki maka tidaklah diragukan lagi bahwa keunggulan nilai warisan budaya di kota Cirebon memiliki nilai yang sangat tinggi dan harus dilestarikan dan dipelihara sebagai bagian dari upaya melestarikan budaya bangsa. Untuk lebih dapat meningkatkan pariwisata di kota Cirebon, destinasi wisata yang bersifat kekinian perlu dikembangkan untuk dapat melayani keinginan dan selera para wisatawan. Koridor Karangwangi, dapat menjadi salah satu strategi pengembangan wisata budaya yang dapat dilakukan. Beberapa upaya untuk dapat mewujudkannya, seperti; penataan fisik jalan yang baik dan indah, rekayasa lalu lintas agar tidak macet, penataan pedestrian agar para pejalan kaki merasa nyaman, penataan ruang terbuka hijau agar kawasan menjadi teduh, penataan street furniture yang menambah estetika jalan, penataan lampu-lampu kota sebagai penerang, penataan billboard agar tertib dan indah, dan lain sebagainya.
\end{abstract}

Kata Kunci : potensi budaya, wisata budaya, wisata kekinian, koridor karangwangi. 


\section{A. PENDAHULUAN}

Saat ini kalau kita lihat perkembangan aktifitas masyarakat di Kota Cirebon terlihat semakin pesat. Berbagai aktifitas perekonomian tumbuh dengan baik seiring dengan semakin baiknya infrastruktur yang ada di kota ini. Begitu juga disektor pariwisata, terlihat dengan semakin meningkatnya angka kunjungan wisatawan yang memiliki kecenderungan naik. Pengembangan kota Cirebon sebagai kota wisata , khususnya kota wisata budaya, sudah sesuai dengan Visi Kepala Daerah Kota Cirebon saat ini yaitu "sehati mewujudkan kota Cirebon sebagai kota kreatif berbasis budaya dan sejarah". Misinya , pertama, adalah Mewujudkan kualitas sumber daya manusia (SDM) kota cirebon yang berdaya saing, berbudaya dan unggul di segala bidang, kedua, Mewujudkan tata kelola pemerintahan yang bersih, akuntabel, berwibawa dan inovatif, ketiga, Meningkatkan kualitas sarana prasarana umum yang berwawasan lingkungan, dan keempat, Mewujudkan keamanan dan ketertiban umum yang kondusif.

Dengan luas wilayah hanya kurang lebih $38 \mathrm{~km} 2$, yang terdiri dari 5(lima) kecamatan dan 22(dua puluh dua) kelurahan, kota Cirebon nyaris tidak memiliki sumber daya alam apapun kecuali peninggalan budaya sejarah yang cukup komplit dan masih terpelihara baik sampai saat ini yang merupakan peninggalan dari berbagai periode sejarah. Diantaranya yang paling banyak meninggalkan bangunan cagar budaya adalah periode kerajaan islam dari abad 15-16 dan periode pemerintahan kolonial pada abad 19. Pada periode kerajaan islam peninggalan budaya sejarah yang ada seperti ; Keraton Kasepuhan, Keraton Kanoman, Keraton Kacirebonan, Keraton Keprabonan, Taman Sari Gua Sunyaragi, Mesjid Agung Sang Cipta Rasa, Mesjid Merah Panjunan, Mesjid Pejlagrahan, Mesjid Jagabayan, Petilasan Sunan Kalijaga, Situs Kejawanan, Situs Ketandan, Situs Makam Syekh Lemah Abang, Situs Makam Syekh Maghribi, Petilasan Pangeran Drajat, dan lain sebagainya. Keraton-keraton yang ada di kota Cirebon sampai saat ini masih aktif dan tetap memegang teguh budaya dan adat istiadatnya.

Pada periode pemerintahan kolonial peninggalan budaya yang ada seperti; Gedung Karesidenan, Gedung Balaikota, Rumah Dinas Bupati Cirebon, Stasiun Kejaksan, Gedung Bank Indonesia, Gedung SMPN 1, SMPN 14 dan SMPN 15, Menara PDAM Parujakan, Stasiun Parujakan, Gedung Bunder Kebumen, Gedung PT.Cipta Niaga, Gereja Pasundan, Gereja Santo Yosef, Gedung Kantor Pos, Gedung Bank Mandiri, Gedung PT.British American Tobacco, Lembaga Pemsyarakatan Kelas 1 Kesambi, dan lain sebagainya. Disamping peninggalan kedua periode sejarah itu juga ada dijumpai peninggalan kebudayaan cina seperti ; Makam Sam Cay Kong, Kelenteng Dewi Welas Asih, Klenteng Talang dan Klenteng Winaon.

Disamping peninggalan budaya sejarah yang berwujud bangunan cagar budaya atau kebendaan (tangible) diatas, kota Cirebon juga banyak memiliki peninggalan yang bersifat bukan kebendaan (intangible), seperti ; kesenian, aktifitas keagamaan, aktifitas kebudayaan, kain batik dan kuliner. Kesenian dalam hal ini seperti seni tari (tari topeng Cirebon), seni musik (musik tarling), seni lukis (lukis kaca) atau seni ukir (ukir topeng). Aktifitas keagamaan seperti adzan pitu yang cukup spesifik karena tidak ada ditempat lain. Aktifitas kebudayaan seperti ; mauludan, ziarah kubur, nadran dan lain sebagainya (Afghoni \& Busro, 2017). Kain batik dari kota cirebon memiliki motif batik yang sangat khas, yaitu motif 'megamendung' yang merupakan karya seni batik yang identik dan bahkan menjadi icon batik daerah Cirebon. Kekhasan motif megamendung tidak saja pada motifnya yang berupa gambar menyerupai awan dengan warna-warna yang tegas, tetapi juga nilai-nilai filosofi yang terkandung didalam motifnya. Sementara untuk warisan kuliner kota Cirebon dikenal banyak orang sebagai daerah yang banyak memiliki maca-macam kuliner, seperti ; nasi jamblang, empal gentong, nasi lengko, tahu gejrot, sate kalong, mie kocok dan lain sebagainya.

Melihat banyaknya potensi peninggalan budaya sejarah yang ada di kota Cirebon, baikyang bersifat tangible maupun intangible, sudah sepantasnyalah kalau pemerintah daerah kota Cirebon menjadikan semua kekayaan peninggalan budaya sejarah tersebut sebagai potensi wisata yang unggulan pada masa yang akan datang. Jarang sekali dijumpai wilayah-wilayah di Indonesia khususnya di Jawa Barat yang 
memiliki potensi wisata budaya seberagam seperti yang ada di kota Cirebon. Potensi wisata budaya yang ada di Kota Cirebon bisa dianggap sebanding dengan yang ada pada Kota Yogyakarta di Provinsi Daerah Istimewa Yogyakarta atau pada Kota Surakarta di Provinsi Jawa Tengah.

\section{B. METODE PENELITIAN}

Penelitian ini bertujuan untuk mengidentifikasi elemen peninggalan budaya yang ada di kota Cirebon baik yang tangible maupun intangible, serta makna atau arti yang terkandung didalamnya dan memberikan wawasan bagi para pemangku kepentingan untuk dapat mengembangkan segala potensi yang ada agar dapat didaya gunakan dalam pembuatan kebijakan pengembangan wisata budaya perkotaan secara maksimal. Metode yang digunakan adalah metode kualitatif, dengan wawancara etnografi, diskusi kelompok fokus dan wawancara langsung. Penggunaan metode ini bertujuan untuk mendapatkan data yang lebih mendalam dan mengandung makna. Oleh karena itu, dalam metode kualitatif tidak menekankan kepada generalisasi (transferability), tetapi lebih menekankan pada makna. Metode kualitatif ini menggunakan penelitian deskriptif, dimana penelitian deskriptif ini hanya menggambarkan sesuatu yang sebenarnya mengenai suatu variabel, dan tidak dimaksudkan untuk menguji hipotesis tertentu, dan tujuan dari penelitian deskriptif ini adalah untuk membuat deskripsi atau gambaran secara sistematis, faktual dan akurat mengenai fakta-fakta, sifat-sifat serta hubungan antar fenomena yang diteliti.

\section{PEMBAHASAN}

\section{Konsep Pengembangan Wisata Kota Cirebon}

Didalam dokumen Rencana Pembangunan Jangka Menengah Daerah (RPJMD) kota Cirebon, permasalahan pembangunan pariwisata di Kota Cirebon secara umum adalah permasalahan mengenai pelestarian budaya. Proporsi pendanaan untuk pelestarian budaya didalam APBD masih sangat terbatas, sementara insentif dan disinsentif terkait pelestarian budaya belum pernah dilakukan dan keterlibatan pihak diluar pemerintah dalam pelestarian budaya juga masih sangat minim. Sedangkan didalam RIPPARDA Kota Cirebon Tahun 2017 - 2025, disampaikan bahwa kebijakan pembangunan kepariwisataan di Kota Cirebon, meliputi, pertama. Kebijakan pengembangan destinasi pariwisata, kedua, kebijakan pengembangan industri pariwisata, ketiga, kebijakan pengembangan kelembagaan pariwisata , dan keempat, kebijakan pengembangan pemasaran pariwisata. Untuk dapat mengimplementasikan kebijakan-kebijakan tersebut telah dirumuskan strategi yang merupakan langkah-langkah yang lebih nyata untuk mewujudkan tujuan pembangunan kepariwisataan di Kota Cirebon. Strategi pembangunan kepariwisataan terdiri dari, strategi pengembangan destinasi pariwisata, strategi pengembangan industri pariwisata, strategi pengembangan kelembagaan pariwisata, strategi pengembangan pemasaran pariwisata.

Bahkan pemerintah Provinsi Jawa Barat juga sudah menetapkan Kota Cirebon sebagai percontohan kota pariwisata. Gubernur Jawa Barat saat ini, Ridwan Kamil, mengatakan, Kota Cirebon dianggap yang paling siap untuk dipoles menjadi kota pariwisata, karena potensi pariwisata yang dimiliki Kota Cirebon sangat besar, dari mulai obyek wisata, tempat kuliner , hingga potensi lainnya. Sementara pada umumnya obyek-obyek wisata yang ada di wilayah-wilayah lain di Provinsi Jawa Barat adalah obyek wisata buatan dan wisata alam seperti ; lansekap, pantai, sungai, danau , hutan atau pegunungan. Saat ini dua per tiga wisatawan di Jawa Barat lebih memilih berwisata di dalam provinsinya sendiri, ini berbeda dibandingkan dengan Jakarta, hanya 20 persen penduduknya yang berwisata didalam kota. Artinya 80 persen wisatawan dari Jakarta adalah peluang emas bagi wilayah terdekat dari Jakarta, seperti banten dan jawa barat. 
Pariwisata bukan saja sebagai sumber devisa, tetapi juga merupakan faktor dalam menentukan lokasi industri dalam perkembangan daerah-daerah yang miskin sumber-sumber alam sehingga perkembangan pariwisata adalah salah satu cara untuk memajukan ekonomi di daerah-daerah yang kurang berkembang tersebut sebagai akibat kurangnya sumber-sumber alam (Yoeti, 1997). Gunn (1988), mendefinisikan pariwisata sebagai aktivitas ekonomi yang harus dilihat dari dua sisi yakni sisi permintaan (demand side) dan sisi pasokan (supply side). Lebih lanjut dia mengemukakan bahwa keberhasilan dalam pengembangan pariwisata di suatu daerah sangat tergantung kepada kemampuan perencana dalam mengintegrasikan kedua sisi tersebut secara berimbang ke dalam sebuah rencana pengembangan pariwisata.

Sektor Pariwisata memiliki peran yang sangat penting bagi Kota Cirebon, hal ini terlihat dari kontribusi pendapatan yang mencapai $40 \%$ dari Pendapatan Asli Daerah (PAD) Kota Cirebon di tahun 2018, ini setara dengan kurang lebih delapan puluh milyar rupiah, yang merupakan sektor terbesar di kota Cirebon yang menyumbang pendapatan asli daerah. Sementara dari jumlah kunjungan wisatawan pada tahun 2018 tercatat 1.072.365 wisatawan yang terdiri dari 1.062.891 wisatawan domestik dan 9.474 wisatawan asing. Pada tahun 2020 Pemerintah Kota Cirebon mentargetkan kunjungan wisatawan dapat mencapai angka dua juta wisatawan. Dengan adanya beberapa infrastruktur transportasi yang sudah beroperasi saat ini, seperti ; jalan tol yang menghubungkan Cirebon dan Jakarta, jalan tol yang menghubungkan Cirebon dan Surabaya, dan beroperasinya Bandara Kertajati di Majalengka yang melayani penerbangan ke beberapa kota di tanah air, rasanya upaya peningkatan jumlah kunjungan wisatawan ke Kota Cirebon bukan hal yang sulit untuk dapat dicapai. Dengan segala potensi yang dimiliki dan dukungan infrastruktur transportasi yang sangat memadai, Pemerintah kota Cirebon harus mampu mengoptimalkan segala sumber daya yang ada untuk mencapai target tadi dengan meningkatkan kemampuan sumber daya manusia dibidang pariwisata dan pendukungnya, menciptakan atraksi-atraksi wisata yang menarik, menyediakan dan menambah fasilitas pendukung pariwisata yang layak dan memadai dan juga menyiapkan infrastruktur lain pendukung pariwisata yang berkualitas baik.

\section{Pengembangan Wisata Budaya}

Menurut Nafila (2013), bahwa pariwisata budaya adalah salah satu jenis pariwisata yang menjadikan budaya sebagai daya tarik utama. Dimana di dalam pariwisata budaya ini wisatawan akan dipandu untuk disamping mengenali sekaligus memahami budaya dan kearifan pada komunitas lokal tersebut. Disamping itu, pengunjung akan dimanjakan dengan pemandangan, tempat-tempat bersejarah sekaligus museum, representasi nilai dan sistem hidup masyarakat lokal, seni (baik seni pertunjukan atau pun seni lainnya), serta kuliner khas dari masyarakat asli atau masyarakat lokal yang bersangkutan.

Sedangkan Goeldner (Nafila, 2013: 1), mengemukakan bahwa pariwisata budaya mencakup semua aspek dalam perjalanan untuk saling mempelajari gaya hidup maupun pemikiran. Definisi ini lebih mengarah pada tujuan pengunjung/atau wisatawan mengunjungi wisata budaya lebih pada untuk memahami hakikat dan membandingkannya dengan kondisi budaya yang dimilikinya sebagai sebuah pemahaman baru, tentunya disamping adanya nilai estetika yang terkandung di dalamnya

Mappi (Asriady, 23: 2016) mengemukakan bahwa beberapa aspek yang termasuk dalam objek pariwisata budaya diantaranya, seperti: adanya upacara kelahiran, taritarian tradisional, musik-musik tradisional, perkawinan, pakaian tradisional (pakaian adat), berbagai macam upacara (seperti turun ke sawah dan upacara panen), bangunan-bangunan bersejarah, cagar budaya, beberapa peninggalan tradisonal, kain tradisional (seperti kain tenun), pemeran festival budaya dan pertunjukan tradisional, hasil tekstil lokal, meseum sejarah dan budaya, serta adat-istiadat lokal lainnya.

Cakupan objek wisata budaya dengan demikian sangatlah luas, namun secara sederhana dapat dikatakan bahwa situs wisata budaya tersebut berasal dari apa yang dipikirkan, dirasakan, dan dilakukan 
oleh manusia selaku pemilik budaya sebagai identitas dari kebudayaan tertentu yang muncul dalam artefact, ideafact dan sosiofact. Wisata budaya yang demikian sangatlah menarik bagi wisatawan yang berada di luarnya, sehingga hal ini menjadi potensi dan daya tarik tersendiri apabila dapat dikemas dengan baik, sehingga akhir-akhir ini pariwisata budaya di Indonesia semakin tumbuh dengan pesatnya pada setiap daerah.

Menurut McKercher dan du Cros (2002), bahwa adanya perkembangan pariwisata budaya berkaitan erat dengan adanya apresiasi dari masyarakat untuk secara terus-menerus menjaga dan memelihara aset budaya atau pusaka budaya mereka yang dalam perkembangannya saat ini semakin dirasakan berkurang. Ahli tersebut kemudian menguraikan bahwa pada dasarnya pariwisata budaya ini paling tidak memiliki empat elemen, seperti pariwisata, bagaimana penggunaan aset-aset budaya tersebut, konsumsi produk/hasil karya, dan wisatawan budaya itu sendiri. Keempat elemen ini perlu dianalisa lebih lanjut untuk lebeih menekankan pada bagaimana pelayanan publik dibentuk guna mengembangkan keempat elemen dasar dalam pariwisata budaya tersebut. Meskipun banyak potensi wisata budaya yang dimiliki oleh kota Cirebon, tapi sepertinya belum dapat secara maksimal di daya gunakan , kalender wisata budaya belum secara rutin digelar, atraksi-atraksi budaya belum banyak diselenggarakan, infrastruktur pendukung pariwisata masih perlu ditingkatkan dan fasilitas pendukung pariwisata perlu diperbanyak agar wisatawan merasa nyaman. Perlu upaya yang komprehensif dan terpadu dalam mengembangkan kota Cirebon sebagai kota wisata budaya dengan melibatkan banyak stakeholders, baik dari unsur pemerintah, DPRD, swasta, masyarakat dan juga para pelaku seni dan budaya, agar Kota Cirebon dapat menjadi kota wisata budaya unggulan di Provinsi Jawa Barat. Banyaknya potensi budaya yang dimiliki dibanding dengan wilayah-wilayah lain di Provinsi Jawa Barat, menjadikan Kota Cirebon memiliki peluang yang sangat besar untuk menjadi kota wisata budaya yang unggul dibanding yang lain.

Kota Cirebon yang didirikan pada tanggal 1 muharram $791 \mathrm{H}$, telah mengalami periode perkembangan sejarah yang cukup panjang. Didalam periode tersebut banyak sekali nilai-nilai maupun peristiwa sejarah yang berlangsung sehingga membentuk karakteristik kota yang ada saat ini. Walaupun begitu sisa-sisa peninggalan masa lampau berupa karya arsitektur, kekayaan seni, tradisi dan budaya tetap bertahan seiring dengan perkembangan jaman sebagai Living Monument. Hal tersebut menjadikan kota cirebon sangat layak untuk disebut sebagai Kota Wisata Budaya atau Kota Pusaka Nasional, bahkan mungkin bisa sebagai Kota Pusaka Dunia (World Heritage City). Dengan banyaknya warisan budaya dari berbagai periode sejarah yang dimiliki maka tidaklah diragukan lagi bahwa keunggulan nilai warisan budaya di kota Cirebon memiliki nilai yang sangat tinggi dan harus dilestarikan dan dipelihara sebagai bagian dari upaya melestarikan budaya bangsa. Kebijakan pembangunan kota cirebon saat ini mengarah pada peningkatan pembangunan dengan karakteristik kota cirebon sebagai kota wisata dengan keunggulan seni dan budaya tradisional sebagai ciri khas dan modal dasar pembangunan. Didalam Rencana Tata Ruang Wilayah (RTRW) Kota Cirebon Tahun 2011-2031 ditetapkan Rencana Kawasan Strategis Kota yang mengakomodasi kepentingan revitalisasi Kawasan Keraton dan Kawasan Gua Sunyaragi sebagai asset pusaka yang tangible dan intangible.

Dari kebijakan tersebut maka secara tidak langsung pemerintah daerah telah memberikan legitimasi dan dukungan bagi upaya penataan, pelestarian dan pengembangan kawasan-kawasan yang memungkinkan untuk menjadi bagian dari peningkatan dan pembentukan karakter wawasan identitas lokal di kota cirebon. Citra kota cirebon sebagai kota wisata yang berbudaya dan islami sebagai bagian dari pelestarian nilai budaya, agama dan tradisi yang telah diajarkan oleh Kanjeng Sunan Gunung Jati sebagai salah satu tokoh Wali Sanga, menjadikan kota ini memiliki nilai yang khas yang tidak dimiliki oleh kotakota lainnya di Indonesia. 


\section{3. "Koridor Karangwangi" sebagai "Malioboro"nya Cirebon}

Untuk lebih dapat lagi meningkatkan pariwisata di kota Cirebon, Destinasi wisata yang bersifat kekinian perlu dikembangkan untuk dapat melayani keinginan dan selera para wisatawan. Obyek-obyek wisata kekinian yang ada di kota saat ini banyak sekali jenis dan ragamnya, seperti ; taman kota, alun-alun, pedestrian, tepian sungai, bangunan-bangunan tua, atau bahkan sebuah ruas jalan. Belajar dari kota-kota lain seperti kota Yogyakarta yang memiliki Jl.Malioboro atau kota Bandung yang memiliki Jl.Asia-Afrika, dimana saat ini obyek-obyek wisata itu menjadi destinasi wisata yang sangat terkenal dan ramai dikunjungi wisatawan, rasanya kota Cirebon cukup memiliki potensi untuk dikembangkan seperti halnya kota Yogyakarta dan kota Bandung.

Koridor Karangwangi, yang merupakan gabungan dua buah ruas jalan, yaitu Jl.Karanggetas dan Jl.Siliwangi, memiliki sejarah yang cukup penting dalam pembentukan kota Cirebon. Dalam perkembangan morfologi kotanya, koridor karangwangi ini selalu menjadi orientasi bagi pertumbuhan kota. Menurut Sulendraningrat dalam Naskah Carita Purwaka Caruban Nagari, diceritakan bahwa masa Kejayaan atau Keemasan Cirebon sebagai Sebuah Kerajaan berdaulat dimulai sejak diangkatnya Syarif Hidayatullah sebagai Sultan Cirebon I sampai dengan berakhirnya pemerintahan Sultan Cirebon ke II yaitu Pangeran Agung atau Panembahan Ratu yakni dari mulai tahun 1479-1649 Masehi. Masa Syarif Hidayatullah, Cirebon banyak melakukan gebrakan-gebrakan politik dengan menjalin persahabatan dengan kesultanan-kesultanan di Nusantara terutamanya dengan Demak. Saat itu Pusat kota caruban nagari sebagai pusat kegiatan politik, agama, ekonomi, maritime, kebudayaan dan infrastruktur.

Pada masa kekuasaan Syarif Hidayatullah (1479 - 1568), tercatat Cirebon melakukan pembangunan besar-besaran, seperti Pembangunan Keraton Pakungwati /Keraton Kasepuhan(1529) , Masjid Agung Sang Cipta Rasa(1498), pasar, alun-alun dan insfrastruktur lainnya. Yang cukup fenomenal adalah Pembangunan jalan yang menghubungkan keraton pakungwati di daerah lemahwungkuk menuju desa pesambangan (gunung jati), sepanjang kurang lebih 5 kilometer, agar dapat dilalui kuda dan pedati, yang sekarang saya sebut sebagai Koridor Karangwangi, karena melalui dua ruas jalan yaitu Jalan Karanggetas dan Jalan Siliwangi. Disana juga dibangun pos penjagaan (jagabayan), yang saat ini dikenal sebagai Masjid Jagabayan, untuk tempat musafir beristirahat sebelum memasuki kota raja/ keraton. Banyak cerita atau mitos yang menceritakan koridor jalan ini, khususnya jalan karanggetas, asal kata getas yang berarti mudah patah menceritakan bahwa karang yang sangat kuat saja bisa getas di tempat itu, maka orang yang sombong meski memiliki ilmu yang tinggi bisa getas di jalan itu. Mitos ini berawal dari cerita tentang Syekh Magelung Sakti seorang kesatria muda yang berambut panjang, konon tengah mencari seorang ulama yang bisa memangkas rambutnya. Kesatria tersebut konon berasal dari Negeri Bagdad Timur Tengah. Kedatangan Syekh Magelung Sakti ke Cirebon lantaran mendengar di daerah ini terdapat orang sakti yang bisa membantu memotong rambutnya . Di sana ia bertemu dengan seorang ulama yang belakangan diketahui bernama Sunan Gunung Jati dan ditempat itulah ia kemudian dipangkas rambutnya oleh sang Sunan dan sang kesatria itu pun bersedia jadi muridnya. Sejak saat itu daerah tersebut dinamai Karanggetas dan kali atau sungai yang melintas di jalan karanggetas dinamai Kali Sukalila, berasal dari kata suka dan Lillahitaala karena Syekhmagelung merasa suka dan sudah ikhlas rambutnya dipotong.

Selain mitos diatas, daerah karanggetas sebenarnya dikenal sebagai daerah yang selalu basah dan tidak stabil (rapuh), hal ini dikarenakan sunan gunung jati pernah membuat kanal yang terhubung ke laut yang berfungsi agar perahu dari laut bisa lebih ke pedalaman, selain itu kanal bisa menampung air laut saat pasang dan juga daerahnya tidak stabil(rapuh) karena banyak dilalui kuda dan pedati sehingga mudah rusak atau getas.

Melihat sejarah yang dimiliki pada Koridor Karangwangi, ini dapat mejadi potensi yang sangat menarik untuk dikembangkan sebagai destinasi wisata baru di kota Cirebon. Koridor Karangwangi bagi 
kota Cirebon dapat dikembangkan sebagaimana layaknya Malioboro bagi Kota Yogyakarta. Koridor Karangwangi (Karanggetas-Siliwangi) memang cukup fenomenal untuk masyarakat Kota Cirebon, di sepanjang koridor jalan itu tersisa warisan bangunan (heritage) yang masih utuh. Sebut saja dari arah utara (Jalan Siliwangi), bangunan Gedung Negara (Karesidenan), Balai Kota Cirebon, masjid Kejaksan, masjid Panjunan, Pendopo Kabupaten Cirebon, Masjid Jagabayan (Karanggetas), Kelenteng Bala Keselamatan (Winaon), Keraton Kanoman dengan pasar dan bangunan-bangunan lain yang telah dihancurkan, seperti gedung mewah Karang Kencana (Hotel Canton/eks Korem) yang sekarang telah berganti wajah menjadi kompleks bisnis yang megah.

Purwanto (2014) menjelaskan bahwa kota harus mempunyai citra yang baik, karena kota dengan citra yang baik maka akan mudah dibayangkan dan meninggalkan kesan bagi siapapun. Kota atau tempat memiliki citra yang baik dapat terjadi dari adanya kenangan yang cukup kuat dalam diri pengamat karena kota tersebut berhasil menjadikan dirinya sebagai tempat memproduksi banyak kenangan bagi siapapun yang menikmatinya. Purwanto (dalam Pettricia, 2014) melanjutkan bahwa hubungan timbal balik manusia dengan lingkungan perkotaan merupakan proses dua arah yang saling terkait, didukung oleh cirisifat yang dapat memberikan citra lingkungan, maupun kejiwaan manusia.

Dalam kajian ruang kota, situasi visual pada suatu koridor merupakan pemandangan yang dilihat dan dipersepsikan oleh pengamat. Wujudnya dapat berupa tampak muka atau fasad, beserta aktivitasaktivitas yang berada di sekitarnya. Situasi visual tersebut yang kemudian menghasilkan citra ruang kota.

Pitana dan Gayatri (2005) menjelaskan bahwa setiap destinasi wisata memiliki citra (image) tertentu, berupa mental maps seseorang terhadap suatu destinasi yang mengandung keyakinan, kessan, dan persepsi. Lebih lanjut, citra pada destinasi wisata terbentuk dari kombinasi antara berbagai faktor yang dapat dikelompokkan ke dalam dua kelompok faktor, yaitu (Pitana., dan Gayatri, 2005): (1) faktor pada destinasi tersebut, seperti: cuaca, pemandangan alam, keamanan, kesehatan dan sanitasi, keramahtamahan, dan lain-lain; dan (2) faktor informasi yang diterima dari berbagai sumber atau fantasi wisatawan sendiri.

Pariwisata adalah salah satu bagian dari hospitality industry (industri keramah-tamahan). Citra memiliki peran yang penting dalam pariwisata. Pentingnya citra dalam kepariwisataan ditegaskan oleh Buck (dalam Pitana., dan Gayatri, 2005) yang memandang bahwa pariwisata adalah industri yang berbasiskan citra, karena citra mampu membawa calon wisatawan ke dunia simbol dan makna. Terkait dengan citra, simbol dan makna, Purwanto (dalam Pettricia, 2014) menerangkan bahwa citra terhadap suatu kota berkaitan erat dengan identitas dari beberapa elemen dalam suatu kota yang berkarakter dan khas sebagai jati diri yang dapat membedakan dengan kota lainnya.

Cirebon adalah kota yang dicitrakan oleh masyarakat sebagai kota yang memiliki potensi wisata budaya yang sangat banyak dan beragam. Begitu juga halnya dengan koridor karangwangi yang memiliki nilai sejarah yang tinggi bagi perkembangan kota Cirebon. Artinya, koridor karangwangi dapat menjadi destinasi utama wisata budaya di Kota cirebon pada masa yang akan datang.

\section{SIMPULAN}

Pengembangan wisata kota Cirebon melalui penataan koridor karangwangi adalah pilihan yang cukup menjanjikan bagi dunia kepariwisataan di kota Cirebon. Perlu niat dan komitmen yang kuat dari Pemerintah Kota dan seluruh stakeholder pariwisata untuk dapat mewujudkan wisata kekinian, seperti hal nya "Malioboro" di kota Cirebon. Sebagai salah satu strategi pengembangan wisata budaya yang dapat dilakukan, perlu beberapa upaya untuk dapat mewujudkan Koridor Karangwangi sebagai destinasi wisata budaya unggulan, seperti; penataan fisik jalan yang baik dan indah, rekayasa lalu lintas agar tidak macet, penataan pedestrian agar para pejalan kaki merasa nyaman, penataan ruang terbuka hijau agar kawasan menjadi teduh, penataan street furniture yang menambah estetika jalan, penataan lampu-lampu 
kota sebagai penerang, penataan billboard atau papan nama jalan agar tertib dan indah, dan lain sebagainya. Kalau semua upaya tadi dapat dilakukan, kota Cirebon akan memiliki destinasi wisata yang baru yang tidak saja mampu mendatangkan banyak wisatawan tetapi juga dapat meningkatkan pendapatan asli daerah dan kesejahteraan bagi warganya.

\section{REFERENSI}

Afghoni, A., \& Busro, B. (2017). Potensi Wisata Tradisi Syawalan di Makam Gunung Jati Cirebon. Jurnal Kepariwisataan: Destinasi, Hospitalitas Dan Perjalanan, 1(2), 72-82. https://doi.org/10.34013/jk.v1i2.12

Antariksa, Basuki.(2018) : Kebijakan Pembangunan Sadar Wisata : Menuju Daya Saing Kepariwisataa Berkelanjutan. Intrans Publishing, Anggota IKAPI, Malang, Jawa Timur.

Atja (1986) : Carita Purwaka Caruban Nagari ; Karya Sastra Sebagai Sumber Pengetahuan Sejarah. Proyek Pengembangan Permuseuman Jawa Barat, Bandung, Indonesia.

Friedmann, John (1987) : Planning in The Public Domain ; From Knowledge to Action. Princeton University Press, Princeton - New Jersey.

Goeldner, Charles,R.,dan Ritchie, J.R.Brent.(2009) : TOURISM ; Principles, Practices, Philosophies. Published by John Wiley \& Sons, Inc, Hoboken, New Jersey.

Girard, LF; Nijkamp, P. (eds.) (2010): Wisata Budaya dan Pembangunan Berkelanjutan lokal, Ashgate, UK

ICOMOS (2009) : World Heritage Cultural Landscape : Description of World Heritage Cultural Landscape with a Bibliography Based on Document Available at the UNESCO-ICOMOS Document Center, ICOMOS 2009.

Judisseno, Rimsky K.(2017) : Aktivitas dan Kompleksitas Kepariwisataan : Suatu Tinjauan Tentang Kebijakan Pengembangan Kepariwisataan. PT.Gramedia Pustaka Utama, Anggota IKAPI, Jakarta.

Lynch, Kevin (1960) : The Image Of The City. The MIT Press, Cambridge- Massachusetts.

Mazmanian, Daniel A., Sabatier Paul A.,(1945) : Implementation And Public Policy. Scott, Foresman and Company, Dallas.

Pitana, I. G. dan Gayatri,P. G. (2005). Sosiologi Pariwisata. Yogyakarta: Penerbit Andi.

Prawiraredja, sugianto, mohammed. (2005) : CIREBON ; Falsafah, Tradisi dan Adat Budaya. Perum Percetakan Negara RI.

Purwanto, E. (2014). Memahami Citra Kota: Teori, Metode, Dan Penerapannya. Semarang: Badan Penerbit Universitas Diponegoro. Online di: http://eprints.undip.ac.id.

Shirvani, Hamid (1985) : The Urban Design Process : Van Nostrand Reinhold, Universitas California Yoeti, Oka, A,. 1996. Pengantar Ilmu Pariwisata. Bandung: Angkasa. 